\title{
“O JOVEM BRASILEIRO NÃO GOSTA DE LER (O QUÊ? E POR QUÊ?)": REFLETINDO SOBRE A QUESTÃO A PARTIR DE DADOS DA PESQUISA RETRATOS DA LEITURA
}

\author{
Paulo Ailton Ferreira da Rosa Junior ${ }^{1}$
}

\begin{abstract}
Resumo: Este artigo tem o objetivo de refletir acerca da educação literária discutindo algumas tensões existentes no que se refere aos anseios escolares em torno das práticas de leitura literária em relação ao que dados indicam que sejam as efetivas práticas de leitura literária a envolverem os jovens em idade escolar. Para tal, propóe-se uma análise de constataçôes da pesquisa Retratos da Leitura divulgada em 2016 à luz das ideias de autores como Zilberman (2001), Paulino (2010) e Mafra (2013), entre outros, a fim de desfazer o senso comum de que "o jovem brasileiro não gosta de ler", esclarecendo especificamente o quê ele não gosta e por que ele não gosta.
\end{abstract}

Palavras-chave: Leitura Literária. Educação literária. Leitores juvenis.

\section{"THE YOUNG BRAZILIAN DOES NOT LIKE TO READ (WHAT? AND WHY?)": REFLECTING ABOUT THE QUESTION BASED ON A DATA ANALYSIS OF THE RETRATOS DA LEITURA RESEARCH}

\begin{abstract}
This article aims to reflect on literary education by discussing some existing tensions regarding school yearlies around literary reading practices in relation to what data indicate that effective literary reading practices involve school - age youth. To do so, it is proposed an analysis of findings from the Reading Portraits research published in 2016 in the light of the ideas of authors such as Zilberman (2001), Paulino (2010) and Mafra (2013), among others, in order to undo common sense that "the young Brazilian does not like to read", specifically explaining what he does not like and why he does not like it.
\end{abstract}

Keywords: Literary reading. Literary ducation. Young readers.

1 Licenciado em Letras - Português e Respectivas Literaturas pela Universidade Federal do Pampa (Unipampa), possui título de especialista em Linguagens Verbais e Visuais e suas Tecnologias pelo Instituto Federal Sul-rio-grandense (IFSul) e é Mestre em Educação pela Universidade Federal de Pelotas (UFPEL). 


\section{Introduçáo}

o universo de expectativas do povo com relação às letras não é positivo. A maioria das pessoas afirma que desistiu de ler, (...) Alegam que não tem paciência para livros. Mas, nas bancas, mulheres compram histórias de amor, homens compram histórias de faroeste ou sacanagem. Não lhes interessa o nome ou a nacionalidade do autor, nem pesquisas formais. Interessa-lhes um gênero, e um mundo narrado com que se identifiquem, emocional e linguisticamente. Só que essas vivências transferenciais foram acusadas, pela própria teoria literária, de serem leitura errada (PAULINO, 2010, p. 80).

Uma breve revisão da história da leitura e dos livros no Brasil nos revela que a assertiva de senso-comum "o brasileiro não gosta de ler", apesar de tendenciosa e potencialmente questionável, parece não ser imotivada. O cerne das origens do seu fundamento aponta para razões históricas nascidas no século XVI. Sobre isso, El Far (2006), por exemplo, nos conta que desde a época da colônia, o acesso ao livro no Brasil já era dificultado. O governo português procurava embargá-lo em duas instâncias: primeiro por que a reprodução impressa em terras brasileiras não era permitida, pois havia temor em torno do conteúdo do que seria produzido e distribuído aqui, uma vez que não haveria controle da Coroa e segundo por que, em decorrência disso, aquele que tivesse interesse em adquirir livros precisaria encarar os infindáveis trâmites burocráticos de importação de um volume de terras lusitanas. Isso acabou por afastar os habitantes da colônia dos materiais de leitura e, consequentemente, dispersar a disseminação da prática.

Ao encontro do cenário descrito, Márcia Abreu (2001), em um apanhado de relatos de viajantes da época, os primeiros a falar sobre a questão das condições culturais no Brasil, relata que eles insistiam em "denunciar as precárias condições de vida intelectual, a ausência de escolas ou a sua inadequação, o número reduzido de livreiros e (...) o desinteresse dos habitantes pela leitura." (ABREU, 2001, p. 140). O tom dessas avaliações acabou sendo o fundador de um modo de interpretar o país que se mantém, em grande medida, até hoje.

Tais ideias propagaram-se ganhando força através de um derivado e documentado processo falho de formação de indivíduos leitores de literatura ao longo do tempo, principalmente dentro de nosso sistema educacional. Regina Zilberman (2005) nos conta que a leitura sempre foi "elemento fundamental na estruturação do ensino brasileiro, pois está no começo da aprendizagem e conduz às outras etapas do conhecimento" (p.79), mas institucionalmente demorou muito para aparecer nos documentos oficiais efetivamente enquanto campo de ensino. Assim, a autora pontua que "a leitura proposta pela escola não se justifica, sem exibir resultado que está além dela" (ZILBERMAN, 2005, p. 81), sempre figurando como meio para atingir outros objetivos, alcançar outros saberes, e não como conhecimento fechado em si.

O período da ditadura militar não nos pode escapar também deste breve resgate das mazelas históricas pelas quais passamos em nossa formação enquanto um país (que almeja ser) de leitores. Entre 1964 e 1985, estando altamente controlado 
pelos mecanismos centralizadores do governo ditatorial, o sistema educacional foi extremamente castigado no que diz respeito aos investimentos para a garantia de sua qualidade. Vivíamos tempos em que Silva (2003) arriscou-se a jogar com a palavra "leitura", transformando-a em "lei-dura", para referir-se a um conjunto de restrições políticas que impediam, de alguma maneira, escolas e pesquisadores de contribuir para a democratização do acesso ao livro, pois, segundo ele constata em seu texto: "Somente a elite dirigente deve ler; o povo deve ser mantido longe dos livros. Os livros, quando bem selecionados e lidos, estimulam a crítica, a contestação e a transformação" (SILVA, 2003, p. 7) e isso era poderia ser uma ameaça ao sistema em vigor.

Assim, provavelmente como herança dessa época, a escola eximiu-se por muito tempo de ensinar a leitura pela fruição, de ensinar a leitura como gosto e desfrute de um exercício intelectual que lida com as nuances da condição humana. E nisso resultaram gerações de maus ou não leitores que fomentam, abastecidos por uma ideia ainda mais perigosa que a da leitura utilitária - a da leitura como acesso a "grandes obras" dos "bons escritores" - o discurso de que "o jovem no Brasil não lê.". Apesar disso, tal discurso não é inquestionável. E para tal, é potencialmente rico recorrer aos dados resultantes da $4^{a}$ edição da Retratos da Leitura no Brasil. Divulgada no ano de 2016 e realizada pelo Ibope por encomenda do Instituto Pró-Livro, ela nos revelou algo na contramão do que se alardeia: aumentou o número de leitores no Brasil em comparação com a edição anterior, que data de 2011.

Estima-se que $56 \%$ da população brasileira acima dos cinco anos de idade leu, pelo menos, partes de um livro nos últimos três meses. Em 2011, o índice era de $50 \%$. A pesquisa revela ainda que houve aumento nos índices de leitura per capita. Se em 2011, um brasileiro lia, em média, quatro livros por ano, em 2015, o índice chegou a 4,96. Apenas na Região Nordeste, onde a população leitora se manteve estável, com os $51 \%$ de leitores já levantados na edição anterior, os índices de leitura per capita caíram de 4,3 livros por ano em 2011 para 3,93 em 2015. De encontro ao que pode ser encarado como um resultado animador é possível argumentar que os critérios utilizados pela pesquisa são bastante rasos, nivelados por baixo, se levarmos em consideração cenários ideais de leitura, e talvez mascarem que esse aumento na porcentagem de leitores não seja algo realmente tão significativo.

Para pensar sobre isso, cabe voltar a algumas ponderações de Abreu (2001). A autora reflete que quando se pensa em representações de leitura, a imagem de leitor que nos vem à cabeça é a daquele indivíduo erudito, que tem sua biblioteca particular, que domina a norma culta da língua e faz uso dela no dia a dia e que aprecia os autores clássicos, as ditas grandes obras, o cânone. Ignora-se aí todo tipo de prática de leitura que não esteja presa ao impresso, que não seja considerada pelos críticos e consequentemente, pela escola como boa literatura, escrita por nomes consagrados que já não estão mais entre nós e apoia-se muito fortemente na ideia de que o mais importante da leitura é o aprender a dominar o bem falar e o bem escrever. Ao que essa imagem parece pouco ou menos frequente do que se gostaria de encontrar, conserva-se então o discurso da ausência da leitura, como parte central da ideia de uma carência cultural brasileira. Ressalta-se que "Essa 
premissa é particularmente importante no discurso pedagógico que insiste no desinteresse dos alunos pela leitura e nas dificuldades daí decorrentes." (ABREU, 2001, p. 148), mas o que a Retratos da Leitura no Brasil nos revela à contramão destas falas, é que são os jovens em idade escolar regular a faixa etária que mais lê no país.

A pesquisa, que avalia leitores de diferentes faixas etárias, apontou que dos 11 aos 13 anos de idade $84 \%$ dos entrevistados pela pesquisa reconheceu-se como leitor, assim como 75\% daqueles com idades entre 14 e 17 anos. Ou seja, os dados apontam que o percentual de jovens leitores é, proporcionalmente, bastante superior ao da média do leitor brasileiro em geral (os 56\% referidos anteriormente), que entra em queda significativa a partir dos 18 anos. Perante tal cenário contraditório, levando em consideração o histórico já remontado e apoiando-se em outras pistas deixadas por outros autores, este artigo busca sintetizar alguns dos dados recolhidos pela referida pesquisa, no que tange às práticas de leitura juvenis, a fim de propor uma análise dos mesmos que discuta o que está implicado por trás do discurso que insiste em repetir que os jovens brasileiros não gostam de ler. Eles não gostam de ler o quê? E por quê?

\section{Desenvolvimento}

Tem sido lugar-comum, por exemplo, ouvir no meio escolar frases como "os jovens não gostam de ler" ou "os jovens não leem", assertiva que, se confrontada com indicadores estatísticos concretos como aqueles apresentados na pesquisa Retratos da Leitura, não se sustentam. Assim, a Retratos de 2016 afirma que 58\% dos jovens leitores entre 11 e 13 anos e $48 \%$ da faixa etária entre 14 e 17 anos responderam que leem, por prazer, livros que eles mesmos escolhem, enquanto apenas, correspondentemente, $12 \%$ e 14\% dizem cultivar hábitos de leitura literária por exigência escolar.

Um viés progressista sobre a educação nos atenta para o fato de que enquanto aparelho ideológico e reproduto de relações sociais na sua dimensão mais conservadora, a escola, de praxe, busca moldar indivíduos com fins de adequálos a perfis do sistema dominante corrente acabando, dessa forma, por naturalizar determinadas assertivas bastante problemáticas. Tal assertiva pessimista sobre os hábitos de leitura juvenis aponta para épocas de cujos ideais, principalmente os de leitor e leitura, já deveriam ter sido superados, denunciando a incapacidade da instituição de dialogar as pedagogias que efetivamente pratica com um mundo que vem acontecendo à sua revelia.

Resulta-nos então uma conclusão evidente: os jovens leem sim, mas nem sempre esta atividade está ligada aos anseios escolares. Quando isso acontece, a escola trata de deslegitimar essas práticas e estabelece-se um cabo de guerra entre o que os alunos querem e efetivamente praticam e o que a instituição lhes impõe enquanto prática validável e que eles ou acolhem por obrigação ou rechaçam escolhendo não fazer. Tal discordância aponta para um histórico embate entre classes e culturas de classes, que, de difícil superação, reverbera no âmbito da vivência juvenil e sua experiência com a leitura, principalmente a literária. 
A Retratos da Leitura de 2016 surpreende com o levantamento de um massivo contingente de leitores que responderam cultivar a prática da leitura por prazer ou lazer: $58 \%$ dos jovens leitores da faixa de 11 a 13 anos dizem ler por "gosto" ou em busca de "distração" contra 37\% que apontaram a leitura como caminho mais utilitarista, citando motivos como "atualização cultural", "conhecimento geral", "crescimento pessoal", "de crença religiosa" e "exigência escolar ou do trabalho", o famoso "ler para quê"; já na faixa dos leitores de idades entre 14 e 17 anos, a leitura "desinteressada" corresponde a $48 \%$ dos jovens; já os que se valem da leitura utilitária são $42 \%$. Essa multiplicidade de visões em torno das práticas e utilidades de leitura não é algo particular de nosso tempo, diversos estudiosos vêm buscando reconstruir a história da leitura, entendendo que os diferentes sujeitos leitores e suas práticas de leitura são consequências do lugar que ocupam no espaço-tempo, visto que registros apontam que, assim como em nossas culturas contemporâneas, as sociedades que nos antecederam também não concebiam ambos da mesma forma.

Para Manguel (2010) são muitos os modos de ler; ler as imagens (todos os suportes e tipos: pedras, papel, desenhos, pintura, fotografia, digital), ler movimentos e gestos, ler o escrito - mas de certo modo, o que todo leitor faz, primariamente, é decifrar signos.

Pactuando com ele, quando nos fala sobre definições mais pragmáticas de leitura, então do texto escrito, Aguiar (2007) afirma que, sem grande rigor, "Podemos definir a leitura como uma atividade de percepção e interpretação dos sinais gráficos que se sucedem de forma ordenada, guardando entre si relações de sentido." (p. 27). Sendo então toda a leitura importante, ao pensar especificamente na leitura literária, ressalta que esta tem um papel social muito mais abrangente: "a literatura dá conta da totalidade do real, pois, representando o particular, logra uma significação humana mais ampla.” (AGUIAR, 2007, p. 28). Caracterizando-se como, nas palavras de Candido (1995), "uma aventura que pode causar problemas psíquicos e morais, como acontece com a própria vida, da qual é imagem e transfiguração. Isso significa que ela tem papel formador de personalidade, mas não segundo as convenções." (p. 176), ainda que lhe rondem muitas quando se tratam das representações que validam no imaginário coletivo as práticas de leitura, inclusive literárias.

Quando o senso comum pensa em um leitor, ele não pensa, automaticamente, em uma jovem grudada à tela de um tablet ou de um celular no transporte público, por exemplo, ou em um morador de rua com um livro esfarrapado em mãos sentado ao lado do contêiner de lixo onde encontrou tal material, ele formula representações muito mais eruditas que dialoguem com a convenção de que ler, principalmente literatura, é para poucos (e bons). Certeau (1994) provoca: "Na hierarquização social, por conseguinte, esconde-se a prática da leitura ou se torna irreconhecível." (p. 267), está validada a leitura do erudito sentado em uma confortável poltrona ou escrivaninha da sua biblioteca particular, mas está negada à do popular em seu trânsito do fazer cotidiano. Por sua vez, os jovens leitores, entendidos por ele como aqueles com menos de vinte anos, representam a categoria que mais tem subvertido os modos de ler. 
Em concordância com essas ideias, Petrucci (1999) assinala que "Em primeiro lugar, ele [o jovem] comporta uma disposição do corpo totalmente livre e individual; pode-se ler deitado no chão, apoiado na parede, sentado embaixo (note-se) das mesas de consulta, com os pés apoiados sobre a mesa" (p. 222), além de recusarem ou usarem de modos imprevistos os suportes tradicionais de leitura, como García (2010) postula: "A cultura juvenil se move por parâmetros distintos aos da cultura acadêmica, escolar e familiar, pois, (...), começou a substituir a "cultura letrada clássica" (...) por uma cultura digital, que se concretiza na convergência de telas." (p. 28). Lê-se no tablet, no celular, nos notebooks, lê-se em fóruns de internet onde é possível discutir sobre o que foi lido e quando se escolhe o impresso, ele pode ser fortemente manipulado, como objeto qualquer, dobrado, amassado ou até mesmo descartado depois de lido.

A pesquisa revela que entre os indivíduos reconhecidos como leitores, o percentual de quem declarou já ter lido livros digitais é 34\%. Já entre quem gosta muito de ler, $38 \%$. Constata-se que $46 \%$ do total de entrevistados asseguraram os livros literários como os mais lidos em meio digital, ocorrendo em tablets e telefones celulares; confirma-se isso através do montante de $56 \%$ dos entrevistados. O computador aparece em segundo lugar como suporte digital mais utilizado para leitura, com 49\%. O kindle, tecnologia pensada especificamente para a aquisição de materiais de leitura, é pouco popular no país, tendo a adesão de apenas $4 \%$ dos entrevistados, provavelmente muito em parte pelo custo do equipamento.

Talvez pela displicência com os protocolos tradicionais mais a facilidade do acesso a eles online $-88 \%$ contou efetuar downloads de livros pela internet - a frequência com que esses jovens leem livros literários por vontade própria contrasta, revelou a pesquisa, com os da população em geral. O percentual da faixa etária dos 11 aos 13 anos que afirmou ler todos os dias ou ao menos uma vez por semana é de $37 \%$ e o da faixa entre 14 e 17 anos é de $33 \%$, contra $19 \%$ da média geral. Para mais, os leitores juvenis muitas vezes não se contentam apenas com a sua leitura do livro, eles vão além, em busca das leituras dos outros e de uma nova leitura sua a partir destas. Eles transitam entre outras mídias buscando as adaptações das histórias que leram em filmes, séries de televisão e plataformas de streamming, games, HQs, engendrando-se em fanfictions, bem como participando em fóruns de discussão na internet, ou mesmo fazendo o caminho inverso, da sala de cinema para a livraria em busca do livro que contém aquela história que acabou de assistir na tela grande. Levando em consideração o fenômeno descrito, Miranda (2009) nos diz então que "Este novo leitor, que nasceu na era virtual, não aceita uma recepção passiva e não entende a leitura como uma atividade isolada. Além disso, considera-se realmente um fã dos livros, assumindo a relação entre erudição, mídia e entretenimento" (p. 1).

Então, não apenas os jeitos de ler são outros, como a própria concepção de leitura vem construindo-se através do tempo como algo que extrapola a simples ideia de decifração do escrito. "Quer se trate do jornal ou de Proust, o texto só tem sentido graças a seus leitores" (CERTEAU, 1994, p. 266), para além da compreensão do encadeamento das palavras, o leitor age interacionalmente, "A 
operação codificadora, articulada a partir dos significantes faz o sentido que não é, portanto, definido por um deposito, por uma "intensão" ou por uma atividade autoral (CERTEAU, 1994, p. 266), mas pelo diálogo entre as experiências e visões de mundo de quem o lê. Assim, ler na pós-modernidade é, por conseguinte, estabelecer um diálogo com os textos e entre os textos, impregnando-os de si mesmo, observando, associando, comparando, contrapondo, complementando, preenchendo as lacunas e fazendo deles matéria do hipertexto do nosso dia a dia.

Mafra (2013) afirma que "Normalmente, ao se usar o termo literatura, tende-se a associá-lo, imediata e exatamente, às obras que marcaram época, que foram reconhecidas pela crítica especializada, ainda que tardiamente: os chamados clássicos." (p. 23), entrementes, as práticas de leitura juvenis apontadas pelos dados da pesquisa Retratos da Leitura indicam outros títulos que não (ou pelo menos ainda não) passaram pela peneira da erudição.

Passeando pela lista "o último livro lido ou que está lendo", encontramos títulos que saltam aos olhos dos mais atentos à cultura juvenil e midiática. Entre os mais citados estão $O$ diário de um banana, de Jeff Kinney, em segundo lugar, e em quarto lugar $A$ culpa é das estrelas, de John Green; já no sétimo lugar empatam Cidades de Papel, também de John Green, A Maldição do Titã - parte da série Percy Jackson, de Rick Riordan e $A$ menina que roubava livros, de Mark Zusak. Pelo oitavo lugar também encontramos várias obras, estas já em circulação entre os jovens há algum tempo, como Crepúsculo, de Stephenie Meyer, Crônicas de Nárnia, de C. S. Lewis (mais encontrado no Brasil em sua edição única, que reúne os sete volumes) e Harry Potter (como definição genérica para qualquer dos volumes citados), de J. K. Rowling.

Uniformemente, todas as obras citadas tratam-se de traduções de textos originalmente escritos em língua inglesa e majoritariamente pertencentes a um gênero conhecido na produção literária em inglês como Young-Adult, textos literários direcionados para indivíduos na idade regular de frequentar a High School americana. Crowe (2001, p. 146) nos diz que por mais de um século, tanto professores, quanto pais e livreiros tem atacado as leituras voltadas para o público adolescente, argumentando que elas não são clássicos e que, por isso, corrompem o espírito leitor dos jovens. Mas defende que tanto quanto bons clássicos, existem bons livros para jovens e que aqueles cuja qualidade textual pode ser posta em dúvida também são encontrados em outros gêneros, inclusive coincidentes aos cânones. $O$ autor ainda desafia dizendo que, por fim, alguns livros para "jovens adultos" não foram canonizados ainda por não estarem entre nós a tempo suficiente para isso (CROWE, 2001, p. 147).

Quando trazidos para nosso país através de suas traduções (e houve um considerável aumento delas nos últimos anos), estes livros acabam no balaio do que aqui categorizamos como literatura infantojuvenil (ou infantil e juvenil). Historicamente, por si só, a literatura infantojuvenil também sofre certo preconceito valorativo, transparecido, por exemplo, nos ditos de autores como Góes (1996) quando esta sai em defesa do gênero dizendo que "não temos o menor preconceito 
quanto à especificação 'infantil e juvenil', pois não a empregamos na leitura em viés de 'pueril ou infantilizado'; ao contrário, para nós, 'infantil e juvenil' remete a exigências de clareza, lucidez (...)" (p. 9). Se tais defesas precisam ser marcadas, é porque os discursos de ataque soam ferrenhos. Este desconforto quanto à literatura infantojuvenil, Mafra (2013) esmiúça em seus conflitos conceituais, quase existenciais:

\begin{abstract}
Observada a partir de suas origens, pode-se destacar o seu caráter pedagógico; se analisada à luz das leis de mercado atuais de produção e distribuição, a literatura infanto-juvenil adquire a face de uma literatura de massa; ao levarmos em conta ainda o transformador aspecto estético que alguns autores e obras tem propiciado, a mesma literatura pode ser vista como literatura de iniciação (MAFRA, 2013, p. 64).
\end{abstract}

Ou seja, nada nos livros infantojuvenis indica qualquer característica de que sejam representantes de um "clássico" reconhecido pela crítica. Além da problemática de pertencer a esse gênero, dois outros traços em comum unem os títulos citados e contribuem na construção de sua quase marginalidade: todos são best-sellers envoltos num forte trabalho midiático e comercial, nenhum deles é reconhecido pela crítica literária como alta literatura (puristas dirão que, inclusive, essas obras nem são literatura) e, consequentemente, isso se reflete excluindo-os das leituras legitimadas pela escola. Torna-se possível então, com base nos dados, afirmar que os jovens preferem fazer leituras que, além de serem produzidas pensando neles como público-alvo, também se caracterizam por serem renegadas pela escola, mas abraçadas pela mídia. Lhes agrada a chamada literatura de massa.

Assim, Petrucci (1999) está correto quando diz que "as práticas de leitura abertamente consumistas, que em nome de uma absoluta liberdade de leitura recusam todo o sistema de valores e toda atitude pedagógica, são cada vez mais extensas" (p. 217). Segundo ele, essas escolhas anárquicas refletem um desejo de autonomia, um anseio comum, sabemos, à faixa-etária em questão: "Trata-se de práticas que pura simplesmente reivindicam a liberdade de leitura independentemente de qualquer cânone existente ou possível (...) os praticantes desses grupos reivindicam o direito de não ser snobs." (PETRUCCI, 1999, p. 217).

Indelegavelmente, muitos críticos estabelecem uma partilha na literatura quanto o que eles julgam ser "bom" e "ruim". As obras reconhecidas pelas academias e literatos da crítica pertencem ao que convencionamos chamar de literatura culta ou erudita. Já a literatura de massa, essa mais à vista de todos nas vitrines das livrarias, é considerada, muitas vezes, uma subliteratura, uma literatura marginal, uma paraliteratura ou nem sequer literatura. Isso, pois o valor de mercado e o valor literário são categorias distintas, o grande público se deixa levar pelos índices de venda como indicador de qualidade de uma leitura, enquanto a crítica se detém em outros parâmetros baseados em análises mais severas dos textos em questão. Isto posto, cabem aqui as palavras de Paulino (2010), quando pensa sobre o assunto: 
Há uma rígida concepção puritana de arte, que envolve a justificação das formas artísticas, seja por sua magnificência interna, seja por seu efeito social positivo. Nunca é o prazer das formas, sensual ou pragmático, o tipo de experiência valorizada pela estética puritana, mas o esforço eticamente justificado, o dever estético. Desta maneira, o puritanismo, de modos diversos, pressupõe obrigações para a arte: obrigatoriamente objetiva, ou transcendente, ou questionadora, ou evolucionária, ou lúdica, ou... popular. O que a estética puritana deseja evitar é a relatividade, o deslocamento da questão do que é arte dominante e dos discursos sobre arte, tais como ainda se apresentam hoje. A caracterização degradada da literatura de massa é uma das manifestações da teoria estética puritana (PAULINO, 2010, p. 82).

Pensando sobre o tema, Sodré (1988) relativiza o discurso que põe literatura de massa e literatura culta em dicotomia: "A diferença das regras de produção e consumo faz com que cada uma dessas literaturas gere efeitos ideológicos diferentes.” (p. 6), portanto, o que as diferencia não é a qualidade do discurso literário, mas a especificidade de seus discursos. Desta forma: "o que importa mesmo são os conteúdos fabulativos (e, portanto, a intriga com sua estrutura clássica de princípio-tensão, clímax, desfecho e catarse), destinados a mobilizar a consciência do leitor, exasperando a sua sensibilidade." (SODRÉ, 1988, p. 16). Isso acontece, pois, como nos diz Huston (2010), somos uma espécie fabuladora, assim, o que o romance Best-seller traz, com ou sem finais felizes como os dos contos de fadas, uma de nossas fabulações mais antigas, é nada mais, nada menos, do que essa estrutura narrativa básica que nos confirma e nos conforta.

A consagração desta literatura como a mais consumida pelas massas se deveu sim, em grande parte, à sua estrutura narrativa, mas não podemos perder de vista o que Watt (2010) nos conta sobre a ascensão do gênero romance, quando ressalta que a revolução industrial promoveu a alfabetização em larga escala, sendo este então também um fator chave; dos salões de leitura burgueses realizados na frança para as casas das camadas menos afortunadas, os romances-folhetim, publicados semanalmente em jornais - que passaram a ter grande circulação alcançando muito mais leitores - popularizaram-se de tal forma ao que, em suas conclusões, eram compilados em edições encadernadas como as que concebemos como os romances atualmente, democratizando um produto até então destinado à elite.

Paz (2004, p. 8), em suas considerações, conta que ainda que adorado pelo público em geral, o folhetim foi muito criticado pelos intelectuais conservadores de sua época, taxado como "literatura industrial". Foi nesse momento em que a prosa literária passou a ser dividida por uma linha de demarcação, e a autora defende que esta linha "forneceu munição para que os defensores do cânone literário conceituassem a literatura de entretenimento como produto de estratagemas mercadológicos e subproduto da literatura culta, destituída de qualquer valor que não seja o comercial" (PAZ, 2004, p. 8).

Entretanto, não é possível fugir do debate que envolve os ditos valores estéticos que possuem as obras classificadas como canônicas, clássicas ou "cultas", pois estes são o que, principalmente, as justificam por ser, segundo a crítica. A visão purista destes mesmos críticos nos diz que "para um texto ser considerado literário, 
ele deveria principalmente ser original e requerer esforço da parte de quem o lê" (PAZ, 2004, p. 8), ou seja, fugir daquela estrutura conhecida que agrada tanto aos consumidores dos best- sellers, "produto de uma indústria que fabrica objetos em série e, por esse motivo, despojada do valor artístico, tudo o que essa narrativa teria para oferecer ao seu público é mais do mesmo, e a encorajar uma visão passiva, superficial e acrítica" (PAZ, 2004, p. 8).

Ainda segundo a pesquisa, título e capa definem mais as escolhas de leitura dos jovens do que possíveis indicações recebidas. Apenas $8 \%$ dos entrevistados entre 11 e 13 anos e 10\% dos entrevistados entre 14 e 17 anos leva em consideração a opinião de algum professor, quando escolhe o que vai ler. Entretanto, a mediação está presente, intrinsecamente, em forma do apelo midiático: todos os livros citados com os que lidamos até aqui têm adaptações fílmicas. Consequentemente, eles estampam capas de revista, anúncios de jornal, são foco de reportagens na televisão, estão espalhados pela internet, gritando para serem conhecidos. No fim das contas é possível afirmar que os jovens leem aquilo que são veladamente convencidos a ler, rejeitando os palpites escolares: "o fato é que a escola tem sido o último referencial de leitura para estes jovens. Justamente ela que deveria favorecer o encontro.". (MAFRA, 2013, p. 24).

Torna-se bastante relevante deter a atenção ao fato de que 33\% do total de entrevistados pela pesquisa respondeu que foi incentivado por alguém quando o assunto é apreço pela leitura. A mãe, ou uma figura feminina, aparece como principal influência, citada por $11 \%$ do montante; já a professora aparece em segundo lugar, apontada por $7 \%$ do montante. Dentro do recorte dos jovens leitores, como resposta para a pergunta sobre fatores que influenciam na escolha de um livro, $11 \%$ na faixa dos 11 aos 13 anos de idade e $12 \%$ dentre os entrevistados que correspondem ao montante de 14 a 17 anos de idade responderam que levam em consideração a indicação de leitura de algum professor. No mesmo recorte, em resposta para a pergunta "Qual foi a pessoa que mais te influenciou a gostar da leitura?", os percentuais correspondentes à opção "algum professor ou professora" foram $12 \%$ na faixa dos 11 aos 13 anos e apenas 9\% na faixa dos 14 aos 17 anos de idade.

Dentre os entrevistados cuja profissão era a da docência 37\% responderam que "gostam pouco" ou "não gostam de ler". Jobim (1994) já alertava para o problema da pouca familiaridade dos alunos recebidos pelo curso de Letras com a leitura de literatura e "Evidentemente, a não familiaridade prévia com a literatura apresenta efeitos concretos na sala de aula." (JOBIM, 1994, p. 76). Enquanto as políticas públicas dos últimos anos têm acertado no esforço de garantir amplamente o acesso material ao livro literário, a contrapartida de investimentos na formação e atualização dos professores enquanto mediadores de leitura têm sido ínfima mesmo nos cursos de Letras. Fomenta-se então o senso comum sobre a literatura como algo sacro, quando, na verdade, é tão feito de matéria bruta mundana, pois de nossas vidas é que fala. 
Assim, uma das causas - se não a principal delas - para a recusa popular pela leitura de literatura, "bem apontada por Regina Zilberman, é o distanciamento entre o imaginário dos textos eruditos e o das pessoas comuns, que dificulta exatamente a identificação." (PAULINO, 2010, p. 81). Se o primeiro passo para envolver-se primariamente com um texto literário é o identificar-se nele de alguma forma, o leitor que encontra no cânone uma de suas primeiras leituras, se não preparado, se não de mãos dadas com um professor mediador que o auxilie a transpassar a barreira linguística construída pelo estilo de época, está mesmo fadado a renegá-lo.

Porém, mesmo afogados em discursos tão ferrenhos de valoração do cânone como única literatura aceita dentro da escola, única literatura de qualidade - ou mesmo única literatura -, Mafra (2013) nos oferece fôlego novo ao atentar-nos para o fato de que, aos poucos, novos estudos vem atestando que parte da crítica especializada começa a questionar o conceito de cânone, buscando "uma dimensão mais plural e menos excludente no trato da produção literária em todo o mundo" (MAFRA, 2013, p .23). Porém, é difícil dizer quando essa visão menos elitizada vai legitimar-se no espaço escolar, uma vez que ela é tão recente e os conceitos tradicionais dos Estudos Literários estão tão engendrados nas práticas do professor que "Herdeiro de uma visão clássica de literatura, é prisioneiro hoje de um anacronismo que o distancia do aluno.” (MAFRA, 2013, p. 24).

O bem da verdade é que, como diz Ceccantini (2009), em diálogo com seus autores de referência Corti e Souza, "a escola ainda não conhece bem o mundo juvenil. De um lado, há pouca pesquisa sobre o assunto; de outro, o conhecimento que existe está longe de ter sido assimilado pela escola e transformado em práticas produtivas" (p. 216). Assentados neste contexto instauram-se estranhamentos entre a escola e a juventude que, responsivamente, não se entendem. Nesse cenário, Mafra (2013) ressalta que:

a literatura mais elaborada, apresentada pelos clássicos e por autores contemporâneos de reconhecida competência pela crítica especializada, é estranha aos alunos adolescentes: ora são inovadoras e radicais desconstruções de estilos tradicionais, ainda herméticas demais para alguém não sintonizado com novas formas de linguagem; ou se apresentam como representação de uma época passada, encasteladas nos famigerados períodos literários, com vocábulos e contextos históricos vistos como anacrônicos e também ultrapassados. Em ambos os casos, a tônica é a rejeição (MAFRA, 2013, p. $50)$.

Um triste desacerto, visto que estes são os mesmos indivíduos que a escola conseguia encantar com atividades de leitura constantes nos anos iniciais, tais como na famigerada "Hora do Conto", presente em tantos cotidianos, e também com uma pluralidade de ofertas de títulos para as crianças disponíveis em suas bibliotecas (quando abertas e acessíveis às crianças). Mas, no ínterim entre a passagem do ensino fundamental para o ensino médio, perde-se essa dimensão polissêmica da literatura no ensino, e tudo passa a girar em torno de conhecimentos que precisam ser abstraídos e sistematizados e até decorados, "Passa a inexistir, nesta forma de enxergar o fenômeno literário, a oposição entre a concepção humanista de 
formação de leitores a longo prazo a partir dos cânones literários e o imediatismo das soluções impostas pelo vestibular" (MAFRA, 2013, p. 58).

Fronte a essa situação de distanciamento entre o que a escola quer que o jovem leia e o que o jovem quer (quando ainda quer) ler, Froehlich (2016) diz que "Resulta desse aspecto a importância de o professor se aproximar do universo de leituras dos alunos, o que não significa renunciar às obras reconhecidas pela tradição numa adesão acrítica à cultura de massa” (p. 167), principalmente porque é responsabilidade da escola garantir o que a cultura de massa, por si só, não garante: o acesso a leituras que não nos conformem, que nos desafiem, desconfortem e que fazem parte de um acervo não tão popularmente ao alcance de todos, mas que precisam ser democratizadas. Leituras que, por acaso (ou não), tem sido consideradas cânones.

Em seu famoso Por que ler os clássicos?, Calvino (1994) defende essa que é uma das missões da escola, ela "deve fazer com que você conheça bem ou mal certo número de clássicos dentre os quais (ou em relação aos quais) você poderá depois reconhecer os 'seus' clássicos” (p. 13), mas não apenas entregando-os aos cuidados dos alunos e sim oferecendo instrumentos, subsídios para que estes alunos consigam fruir tais textos. $\mathrm{O}$ fracasso da leitura escolar entre a juventude é tão grande que, em determinados casos, os títulos sequer são oferecidos aos alunos. Em lugar da leitura deles, figura a leitura de resumos e excertos descontextualizados em livros didáticos e páginas da internet; "a escola e a universidade deveriam servir para fazer entender que nenhum outro livro diz mais sobre o livro em questão; mas fazem de tudo para que se acredite no contrário" (CALVINO, 1994, p. 12).

Esse estranho movimento que, mais do que negar, mediocriza o contato com o texto literário trabalha a favor, mesmo que sem saber, de um contingente ao qual segue não interessando que as massas desfrutem de certos direitos, como as obras literárias consideradas clássicas, tal qual denuncia Paulino (2010):

Querer afastar a literatura da vida é uma medida profilática que parece estar dando certo e vem sobrevivendo até mesmo à superação das teorias legitimadoras de tal afastamento. Os autores ainda gozam a mística do sujeito absoluto com sua criação absoluta, embora ela tenha sido denunciada por toda uma crítica do idealismo. (...) Uma intelectualidade aristocrática continua trancando as portas das artes para o povo (PAULINO, 2010, p. 82).

Entre o desprestigio pelas leituras feitas à revelia e o descuidado com as leituras que oferece, a escola vem confirmando, como já disse Regina Zilberman (2001, p. 46), ser "o avesso do livro", sufocando e suprimindo a imaginação.

\section{Conclusão}

Realizada pela primeira vez no ano 2000 e computando até agora quatro edições, a pesquisa Retratos da Leitura no Brasil tem tido como objetivo central "Conhecer o comportamento leitor medindo a intensidade, forma, limitações, motivação, representações e as condições de leitura e de acesso ao livro - impresso e digital - pela população brasileira." (Instituto pró-livro, 2015, p.8). Assim sendo, 
vem constituindo-se como a pesquisa de maior fôlego e mais relevante no que tange ao mapeamento das práticas de leitura, principalmente as literárias, no Brasil, país histórico e culturalmente marcado pela dificuldade de acesso aos materiais de leitura por parte da população e consequentemente pouco fluente nas práticas que deles decorrem.

Das conclusões presentes nesta última edição, divulgada no ano de 2016, tomou- se como estopim para o desenvolver deste artigo a de que são os jovens em idade escolar regular aqueles que mais leem no país, confrontando-a com uma das falas mais recorrentes entre professores de Língua Portuguesa e Literatura: a de que o jovem no Brasil "não gosta" de ler. Ora, se "não gosta", como pode então figurar enquanto maior contingente leitor da pesquisa? Buscou-se entender, então, a partir de uma problematização teórica dos dados que apoiavam a referida conclusão da pesquisa, "o que o jovem no Brasil não gosta de ler e por quê?", chegando à produção de algumas conclusões que vão ao encontro da ideia de que há um montante dos jovens que, sim, gosta de ler, mas não os livros propostos pela escola, que trata de deslegitimar ou não reconhecer as suas práticas e perfis contemporâneos de, respectivamente, leitura e leitor.

Assim sendo, com a emergência de novas posturas em relação aos textos escritos, que hoje podem ser lidos também nas telas de aparelhos eletrônicos, em meio ao movimento das ruas, tendo sido concebidos inclusive por escritores marginais, e não mais apenas em sacralizados ambientes silenciosos, com edições de luxo em mãos nas quais estão impressos grandes textos literários considerados clássicos, a escola tem se mantido presa as suas tradicionais e antiquadas concepções, ratificadas nas práticas pedagógicas e nos discursos senso-comum, instaurando uma dicotomia na recepção dos alunos quando se fala em leituras escolares e em leituras feitas no que Mafra (2013) caracterizou como à revelia da escola.

Enquanto a Escola, justificavelmente, por seu compromisso com a democratização de uma cultura que não transita tão facilmente no cotidiano popular, fora dos seus muros, preconiza o encontro com o cânone elegido pela crítica literária, dentro dos seus limites, os leitores juvenis têm preferido, por falarem mais facilmente às suas realidades, as leituras que são dirigidas à sua faixa etária e às vezes até produzidas por iguais. Alardeadas principalmente pelas mídias, não apenas por caracterizarem-se como objetos de consumo que fomentam o mercado editorial de nossa sociedade capitalista, mas também por apelarem fortemente aos jovens e suas culturas, essas leituras tem sido amplamente consumidas e não reconhecidas como legítimas pelos professores, que seguem baseando-se apenas no que diz a tradição e reproduzindo o senso-comum de que seus alunos não leem.

Assim, para que a balança se equilibre, urge que a Escola reveja suas concepções e reflita isso em suas práticas pedagógicas. Não se trata de abandonar o que, com razão, acredita ser o adequado para seu público: conhecer a ampla coleção do cânone, que faz parte da história da produção intelectual humana, formar leitores capazes de se embrenhar em textos com níveis de maior complexidade do que os de oferta mercadológica, assim formando indivíduos com capacidades mais 
elevadas de decodificação e interpretação do escrito, etc.; mas abrir-se também para o contemporâneo, para o que chega de maneira mais fácil ao seu público-alvo, os jovens, e apoiar-se nele como um dos meios para atingir esse seu intuito final e maior. Se o jovem não lê o cânone por gosto, por fruição, é porque a escola está falhando na mediação entre eles e estes textos e tal posicionamento precisa ser, então, revisto, reelaborado, reconcebido a partir de uma assunção das culturas juvenis.

Repetir à exaustão que ao jovem brasileiro não interessa a prática da leitura, é uma posição problemática. A crise na leitura não se trata disso. Os números da pesquisa Retratos da Leitura e uma olhada mais atenta às culturas juvenis denunciam o fato. É claro que, em determinados contextos de exclusão social e marginalização, realmente a prática da leitura ficará em último lugar aos interesses juvenis. Porém, para além disso, a crise na leitura concentra-se na, e é sobre a, Escola, acima de tudo. Por isso, é preciso que professores tenham sempre em mente a frase que marca a finalização desta discussão: "A leitura não está no fim de sua história, e sim no começo da trajetória individual de seus adeptos" (ZILBERMAN, 2001, p. 56).

\section{Referências}

ABREU, Márcia. Diferença e desigualdade: preconceitos em leitura. In: MARINHO, Marildes (org.). Ler e navegar: espaços e percursos de leitura. Campinas: Mercado de Letras/ALB, 2001.

AGUIAR, Vera Teixeira. Leitura e Conhecimento. In: Revista Signo. Santa Cruz do Sul, v.32 n.53, p. 26-41, dez.2007.

CALVINO, Italo. Porque ler os clássicos? São Paulo: Companhia das Letras, 1994.

CANDIDO, Antonio. A literatura e a formação do homem. In: Revista Ciência e Cultura, v.24, n.9, p.803-809, set.1972.

CECCANTINI, João Luis. Leitores iniciantes e comportamento perene de leitura. In: SANTOS, Fabiano dos; MARQUES NETO, José Castilho; RÖSING, Tânia M. K.

Mediação de leitura: discussões e alternativas para a formação de leitores. São Paulo: Global, 2009.

- Mentira que parece verdade: os jovens não leem e não gostam de ler. In:

FAILLA, Zoara (Org.). Retratos da leitura no Brasil 4. Rio de Janeiro: Sextante, 2016.

CERTEAU, Michel de. Ler: uma operação de caça. In: . A invenção do cotidiano: 1. Artes de fazer. Petrópolis: Vozes, 1994.

COUTINHO, Eduardo. Fronteiras imaginadas: o comparatismo e suas relações com a Teoria, a Crítica e a Historiografia literárias. In: Literatura comparada na América Latina: ensaios. Rio de Janeiro: EdUERJ, 2003. 
CROWE, Chris. Adult Literature: The Problem with YA Literature. In: The English Journal, vol. 90, No. 3, The Lure of Young Adult Literature, jan., 2001.

EL FAR, Alessandra. O livro e a leitura no Brasil. Rio de Janeiro: Jorge Zahar Editor, 2006 .

FROEHLICH, Márcia. Formação do leitor no ensino médio: mitos e possibilidades. In: MARTINI, Marcus de; OLIVEIRA, Raquel Trentin; FELIPPE, Renata Farias de. (org.). Literatura na escola: teoria, prática e (in)disciplina. Santa Maria: UFSM/PPGL, 2016

GARCÍA, Alberto Martos. Os jovens diante das telas: novos conteúdos e novas linguagens para a educação literária. In: RETT'TENMAIER, Miguel; RÖSING, Tânia Mariza K. (Orgs). Questões de literatura na tela. Passo Fundo: UPF, 2010.

GOÉS, Lúcia Pimentel. Olhar de Descoberta. São Paulo: Mercúrio, 1996.

HUSTON, Nancy. A Espécie Fabuladora: Um breve estudo sobre a humanidade. Porto Alegre: L\&PM, 2010.

INSTITUTO PRÓ-LIVRO. Retratos da Leitura no Brasil. São Paulo: Instituto Pró- Livro, 2015. Disponível em http://prolivro.org.br/home/images/2016/Pesquisa_ Retratos_da_Leitura_no_Brasil_-_2015.pdf Acesso em 14/11/16

JOBIM, José Luiz. A crítica da teoria: uma análise institucional. In: Revista Brasileira de Literatura Comparada. São Paulo: ABRALIC, No. 2, p.69-78, 1994.

MAFRA, Núbio Delanne Ferraz. Leituras à revelia da escola. Londrina: Eduel, 2013.

MANGUEL, Alberto. Uma história da leitura. Tradução de Pedro Maia Soares. São Paulo: Companhia das Letras, 2010.

MIRANDA, Fabiana Móes. Fandom: um novo sistema literário digital. In: Hipertextus Revista Digital. No. 3, 2009. Disponível em http://hipertextus.net/volume3/FabianaMoes-MIRANDA.pdf, Acesso em 05/07/17.

PAULINO, Graça. MARIA, Cristina (org.). Das leituras ao letramento literário. Belo Horizonte: FaE/UFMG; Pelotas: UFPel, 2010.

PAZ, Eliane H. Massa de Qualidade. In: I Seminário Brasileiro sobre Livro e História Editorial, Rio de Janeiro: Casa de Rui Barbosa novembro, 2004. Disponível em http:// livroehistoriaeditorial.pro.br/pdf/elianehpaz.pdf, Acesso em 04/07/17.

PETRUCCI, Armando. Ler por ler: um futuro para a leitura. In: CAVALLO, Guglielmo; CHARTIER, Roger (Orgs.). História da leitura no mundo ocidental 2. São Paulo: Editora Ática, 1999.

SILVA, Ezequiel Todoro da. Conferências sobre leitura. Campinas, SP: Autores Associados, 2003. 
SODRÉ, M. Best-Seller: a literatura de mercado. Rio de Janeiro: Ática, 1988.

ZILBERMAN, Regina. Fim do livro, fim dos leitores?. São Paulo: Editora Senac São Paulo, 2001.

Leitura Literária e outras leituras. In: GALVÃO, Ana M. de O.; BATISTA, Antônio A. G. (Orgs.). Leitura: práticas, impressos, letramentos. 2. Ed., 1. Reimp. Belo Horizonte: Autêntica, 2005.

WATT, Ian. A ascensão do romance: estudos sobre Defoe, Richardson e Fielding. São Paulo: Companhia das Letras, 2010. 